\title{
Combined effect of nitric acid and sodium hydroxide pretreatments on enzymatic saccharification of rubber wood (Heavea brasiliensis)
}

\begin{abstract}
A combinatorial nitric acid and sodium hydroxide pretreatment for improving the enzymatic saccharification of rubber wood was proposed in this study. Effects of pretreatment time, temperature as well as nitric acid and sodium hydroxide concentrations on glucose yield were investigated. Rubber wood sawdust was sequentially pretreated with dilute nitric acid and dilute sodium hydroxide, respectively. The pretreated samples were hydrolyzed using cellulase together with $\beta$-glucosidase at enzyme loadings of $25 \mathrm{FPU}$ and $60 \mathrm{CBUg} / \mathrm{cellulose}$, respectively. Results from the enzymatic hydrolysis experiments showed that a glucose yield of $95 \%$ was achieved (within $24 \mathrm{~h}$ of hydrolysis) with rubber wood sample pretreated using $6 \% \mathrm{HNO} 3$, at $100^{\circ} \mathrm{C}$ for $60 \mathrm{~min}$ followed by $1 \% \mathrm{NaOH}$ at $90^{\circ} \mathrm{C}$ for $30 \mathrm{~min}$. Comparison of these results with those reported in literature demonstrated that combining nitric acid and sodium hydroxide pretreatments resulted in higher rate of hydrolysis and better cellulose digestibility.
\end{abstract}

Keyword: Lignocellulose; Bioethanol; Pretreatment; Rubber wood; Enzymatic saccharification 